This item was submitted to Loughborough's Research Repository by the author.

Items in Figshare are protected by copyright, with all rights reserved, unless otherwise indicated.

\title{
Influence of brisk walking on appetite, energy intake, and plasma acylated ghrelin
}

PLEASE CITE THE PUBLISHED VERSION

http://dx.doi.org/10.1249/MSS.0b013e3181ba10c4

PUBLISHER

(c) American College of Sports Medicine

VERSION

AM (Accepted Manuscript)

LICENCE

CC BY-NC-ND 4.0

REPOSITORY RECORD

King, James A., Lucy K. Wasse, David R. Broom, and David J. Stensel. 2019. "Influence of Brisk Walking on Appetite, Energy Intake, and Plasma Acylated Ghrelin”. figshare. https://hdl.handle.net/2134/10167. 
This item was submitted to Loughborough's Institutional Repository (https://dspace.lboro.ac.uk/) by the author and is made available under the following Creative Commons Licence conditions.

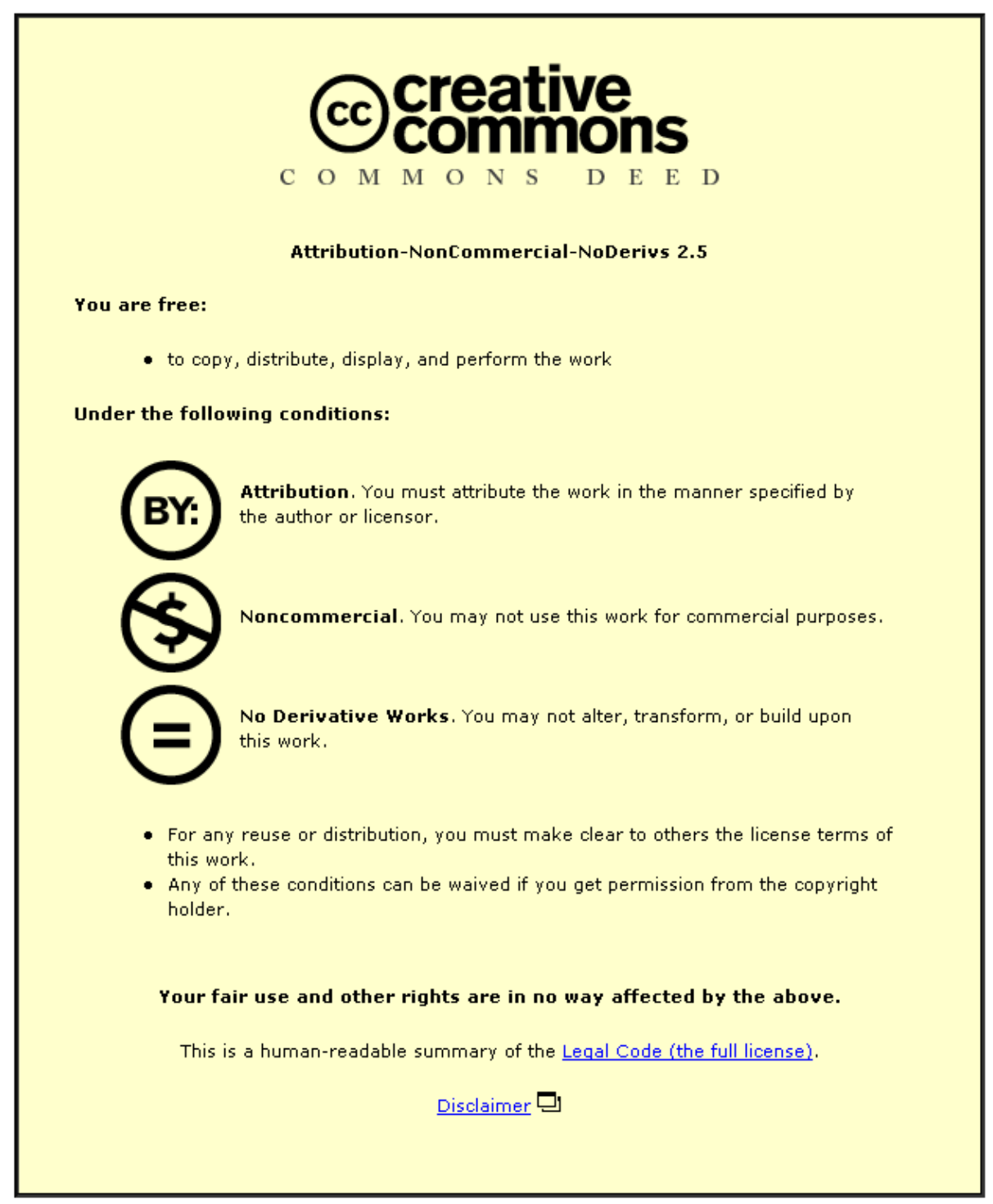

For the full text of this licence, please go to: http://creativecommons.org/licenses/by-nc-nd/2.5/ 
The influence of brisk walking on appetite, energy intake and plasma acylated ghrelin

James A King ${ }^{1}$, Lucy K Wasse ${ }^{1}$, David R Broom ${ }^{2}$ and David J Stensel ${ }^{1}$

1 Loughborough University, UK

2 Sheffield Hallam University, UK

\section{Running Title}

Acylated ghrelin, appetite, exercise

\section{Correspondence}

Dr David Stensel

School of Sport and Exercise Sciences

Loughborough University

Leicestershire

LE11 3TU

UK

Phone: $+44(0) 1509226344$

Fax: $\quad+44(0) 1509226301$

E-mail: D.J.Stensel@lboro.ac.uk

\section{Disclosures}

This project received financial support from the Ramblers' Association. 


\begin{abstract}
Purpose. This study examined the effect of an acute bout of brisk walking on appetite, energy intake and the appetite stimulating hormone - acylated ghrelin. Methods. Fourteen healthy young males (age $21.9 \pm 0.5$ years, BMI $23.4 \pm 0.5 \mathrm{~kg} \cdot \mathrm{m}^{-2}, \mathrm{VO}_{2} \max 55.9 \pm 0.7$ $\mathrm{mL} \cdot \mathrm{kg}^{-1} \cdot \mathrm{min}^{-1}$ ) completed two eight hour trials (brisk walking and control) in a randomizedcounterbalanced fashion. The brisk walking trial commenced with 60 minutes of subjectively paced brisk walking on a level motorised treadmill after which participants rested for seven hours. Participants rested for the duration of the control trial. Ad Libitum buffet meals were offered twice during main trials (1.5-2 and 5-5.5 h). Appetite (hunger, fullness, satisfaction and prospective food consumption) was assessed at 30 minute intervals throughout. Acylated ghrelin, glucose, insulin and triacylglycerol were determined from plasma. Results. Sixty minutes of brisk walking $\left(7.0 \pm 0.1 \mathrm{~km} \cdot \mathrm{hr}^{-1}\right)$ yielded a net (exercise minus resting) energy expenditure of $2008 \pm 134 \mathrm{~kJ}$ yet did not significantly influence appetite, energy/macronutrient intake or the plasma concentration of acylated ghrelin, either during or after exercise $(P>0.05)$. Participants did not compensate for energy expended during walking therefore a deficit in energy was induced $(1836 \mathrm{~kJ}, 439 \mathrm{kcal})$ relative to control. Conclusion. This study demonstrates that despite inducing a moderate energy deficit, an acute bout of subjectively paced brisk walking does not elicit compensatory responses in acylated ghrelin, appetite or energy intake. This finding lends support for a role of brisk walking in weight management.
\end{abstract}

Key Words. Exercise, energy balance, gut hormones 


\section{Introduction}

Paragraph Number 1. Walking can provide many health benefits lessening the risk of a range of chronic health conditions, particularly those relating to cardiovascular disease and type 2 diabetes mellitus $(31,7,28)$. Less clear is the influence of walking on energy balance and weight control (31). This is concerning given the rising global prevalence of overweight and obesity (20). Enhancing levels of physical activity within the population has been highlighted as important in combating present trends (12) and as walking is the most popular modality of physical activity undertaken on this scale a definitive understanding of its influence on energy balance and weight control is necessary.

Paragraph Number 2. Consistent with any form of physical exertion walking induces the expenditure of energy. Therefore, if performed frequently, walking should make an important contribution to successful energy balance. This account may be too simplistic however as the consensus of evidence fails to demonstrate a consistent effect of walking on indices of weight control (31). Compensatory responses following exercise may be implicit in this regard (23). In particular, it is possible that an augmentation of appetite and energy intake may occur following the expenditure of energy through physical activity (23). It is foreseeable that an increase in energy intake following exercise could negate the energy expended during an acute bout of walking. Variability in appetite and energy intake responses after both discrete and chronic episodes of walking may explain the inconsistent findings reported previously (31).

Paragraph Number 3. Studies examining the effect of exercise on both appetite and energy intake typically demonstrate a lack of influence in the short-term (2). Studies examining the specific influence of walking on appetite (19) and energy intake (19, 18, 33) typically 
confirm this finding although one study has found a suppression of hunger following 20 minutes of brisk walking (39).

Paragraph Number 4. The regulation of appetite and energy intake is under complex neuroendocrine control involving both centrally and peripherally mediated systems (32). Gut peptides within the enteric endocrine system are integral to this process and efforts seeking to define how these peptides respond to exercise have recently begun $(26,29)$. Of the gut peptides regulating energy homeostasis ghrelin remains unique as the only known circulating orexigen (25). The influence of acute exercise on plasma total ghrelin is contentious however as studies have reported no change in ghrelin during or following exercise $(6,27)$ in addition to both increases $(8,15,34)$ and decreases $(38,40)$. Acylation of ghrelin is thought to be essential for appetite regulation, therefore assessment of total ghrelin may mask important changes in acylated ghrelin. Indeed, following a cycling stimulus, Marzullo and co-workers (30) recently found no change in plasma concentrations of total ghrelin despite acylated ghrelin being suppressed. Furthermore, concomitant suppressions of acylated ghrelin and hunger have been reported following high intensity bouts of running and resistance exercise $(4,5)$. Despite this, how acylated ghrelin responds to low intensity exercise such as walking remains unknown. In addition to this, the question of whether exercise-induced changes in acylated ghrelin have implications for actual food intake is yet to receive attention.

Paragraph Number 5. The purpose of the present study was to examine the appetite, energy intake and the plasma acylated ghrelin response for an extended period of time after an acute bout of exercise. Specifically, the response of these variables during and for several hours after a 60 minute bout of brisk walking was examined. We sought to assess both the immediate and prolonged influence of walking on acylated ghrelin, appetite and energy 
intake. The findings reported here may have implications concerning the promotion of walking for successful weight control.

\section{Methods}

Paragraph Number 6. Participants. Following ethical advisory committee approval fourteen healthy males (18-26 years) gave their written informed consent to participate. Participants were non-smokers, had no known history of cardiovascular/metabolic disease, were not dieting or taking medication and were not obese $\left(\mathrm{BMI} \leq 29.9 \mathrm{~kg} \cdot \mathrm{m}^{2}\right)$ or hypertensive (resting blood pressure $<140 / 90 \mathrm{mmHg}$ ). Table 1 details the participant characteristics.

\section{Insert Table 1 here}

Paragraph Number 7. Screening and Familiarisation. Before partaking in main trials participants visited the laboratory to undergo screening, familiarisation and preliminary anthropometric and exercise testing. Questionnaires were completed to assess health status, physical activity habits and food preferences. Height was measured to the nearest $0.1 \mathrm{~cm}$ using a stadiometer (Seca Ltd, Germany) and body weight was measured to the nearest 0.01 $\mathrm{kg}$ using a balance beam scale (Avery Industrial Ltd., Leicester, U.K.). Body mass index (BMI) was then calculated. Waist circumference was determined as the narrowest part of the torso (above the umbilicus and below the xiphoid process). Body density was estimated via subcutaneous fat measurements (13) made using skinfold callipers (Baty International, West Sussex, UK) and body fat percentage was ascertained (35).

Paragraph Number 8. Exercise Tests. A submaximal treadmill walking test was completed on a level motorised treadmill to ascertain each participant's subjective brisk walking speed. 
Participants were told that brisk walking was defined as an exercise intensity yielding a mild shortening of breath yet still enabling the individual to converse. During the test the treadmill speed was initially adjusted until a suitable pace was determined. Participants then maintained this speed for five minutes. In the final minute of the test heart rate was measured using short-range telemetry (Sports tester $\mathrm{PE}_{3000}$, Polar Electro, Finland) and ratings of perceived exertion (RPE) were recorded (3). After sufficient rest maximum oxygen uptake was assessed via an incremental treadmill run to exhaustion on a level motorised treadmill (36). One minute samples of expired air were collected in the final minute of each stage. Final collections were taken when participants could continue for one minute only.

Paragraph Number 9. Main Trials. Participants completed two main trials (brisk walking and control) in a randomized-counterbalanced fashion. Trials were separated by at least one week. Participants began main trials in the fasted state having consumed only water since 11:00 pm on the evening immediately prior to main trials. Each trial commenced between 09:00-09:30 am and lasted $8 \mathrm{~h}$. On trial days participants travelled to the laboratory via motorised transport however if this was not possible it was ensured that any exertion prior to trials was minimal. The brisk walking trial commenced with a 60 minute subjectively paced brisk walk on a level motorised treadmill (Runrace, Technogym, Gambettola, Italy). The initial walking pace was that ascertained in the preliminary laboratory visit although adjustments were made if discomfort was experienced. Samples of expired air were collected at 15 minute intervals throughout to determine energy expenditure and substrate oxidation (17). Heart rate and RPE were also assessed at these times. Following the walk participants rested for $7 \mathrm{~h}$ (sitting reading, writing, working at a computer or watching television). Participants rested for the entire duration of the control trial. In order to estimate the net energy expenditure of brisk walking (gross energy expenditure of walking minus resting 
energy expenditure), samples of expired air were collected in the semi-supine position during the first hour of the control trial to estimate resting metabolic rate. At baseline, $0.5 \mathrm{~h}, 1 \mathrm{~h}$ and at 30 minute intervals thereafter, ratings of appetite (hunger, satisfaction, fullness and prospective food consumption) were assessed using $100 \mathrm{~mm}$ visual analogue scales (16). Environmental temperature and humidity were also measured at these times using a handheld hygrometer (Omega RH85, Manchester, UK). Figure 1 provides an overview of the protocol for the main trials. Further details of these trials are given in the paragraphs below.

\section{Insert Figure 1 here}

Paragraph Number 10. Ad Libitum Buffet Meals. During main trials participants consumed food from an ad libitum buffet meal provided twice throughout (1.5-2 $\mathrm{h}$ and 5-5.5 $\mathrm{h})$. The buffet foods were identical prior to each meal (Appendix A) and provided diversity in protein, fat and carbohydrate content in order to facilitate the detection of macronutrient preferences. Food was presented in excess of expected consumption. Participants were told to eat until satisfied and that additional food was available if desired. Participants consumed meals in isolation so that social influence did not constrain food selection. Food consumption was ascertained by weighing buffet items before and after each meal. The energy and macronutrient content of the items consumed was ascertained using manufacturer values. Prior to main trials acceptability of the buffet food items presented was ensured after completion of a food preference questionnaire. The questionnaire required participants to rate pre-selected food items on a scale ranging from one (dislike extremely) to ten (like extremely). Questionnaires were examined to ensure that the food items available would be to the taste of each individual. Distaste for the buffet items (rating 4 items $\leq 4$ ) resulted in participant non-inclusion. 
Paragraph Number 11. Physical Activity and Dietary Standardization. Participants completed a weighed food record of all items consumed within the $24 \mathrm{~h}$ preceding their first main trial. Alcohol and caffeine were not permitted during this period. This feeding pattern was replicated prior to subsequent trials. Participants also refrained from strenuous physical activity during this time.

Paragraph Number 12. Blood Sampling. A cannula (Venflon, Becton Dickinson, Helsinborg, Sweden) was inserted into an antecubital or a forearm vein while participants lay in a semi-supine position $\sim 30$ minutes before main trials commenced. Venous blood samples were taken into pre-chilled $4.9 \mathrm{~mL}$ monovettes (Sarstedt, Leicester, UK) at baseline, 0.5, 1, $1.5,2,2.5,5,5.5,6,7$, and $8 \mathrm{~h}$ to measure plasma acylated ghrelin. To prevent the degradation of acylated ghrelin by protease these monovettes contained EDTA and a $50 \mu \mathrm{L}$ solution containing potassium phosphate buffer $(0.1 \mathrm{M}), P$-hydroxymercuribenzoic acid (100 $\mathrm{mM})$ and sodium hydroxide $(10 \mathrm{M})$. Monovettes were spun at $1,287 \mathrm{~g}$ for 10 minutes in a refrigerated centrifuge at $4{ }^{\circ} \mathrm{C}$. The plasma supernatant was then dispensed into a storage tube and $100 \mu \mathrm{L}$ of hydrochloric acid $(1 \mathrm{M})$ was added per millilitre of plasma. Thereafter, samples were spun at $1,287 \mathrm{~g}$ for 5 minutes in a refrigerated centrifuge prior to storage. Additional blood samples were collected into pre-chilled $9 \mathrm{~mL}$ EDTA monovettes (Sarstedt, Leicester, UK) at baseline, $0.5,1,1.5,2,2.25,2.5,3,3.5,5,5.5,5.75,6,6.5,7$ and $8 \mathrm{~h}$ for the determination of plasma glucose and triacylglycerol. Plasma insulin was determined from collections at $0,1,1.5,2,2.25,2.5,3.5,5,5.5,5.75,6,7$ and $8 \mathrm{~h}$. These monovettes were spun at 1,681 $g$ for 10 minutes in a refrigerated centrifuge (Bukard, Hertfordshire, U.K.) at 4 ${ }^{\circ} \mathrm{C}$. The plasma supernatant was then aliquoted into $2 \mathrm{~mL}$ Eppendorf tubes prior to storage for analysis later. 
Paragraph Number 13. All blood samples were taken in the semi-supine position except for $0.5 \mathrm{~h}$ collections during the brisk walking trial where subjects straddled the treadmill. To avoid sample dilution residual saline was discarded using a $2 \mathrm{~mL}$ syringe prior to each collection. Patency of the cannula was maintained by flushing with non-heparinised saline (0.9 \% w/v Sodium Chloride, Baxter Healthcare Ltd., Norfolk, U.K.). To estimates changes in plasma volume (11) duplicate $20 \mu \mathrm{L}$ blood samples were collected into micropipettes and triplicate $20 \mu \mathrm{L}$ samples were collected into heparinised microhaematocrit tubes to determine blood haemoglobin and haematocrit concentrations respectively.

Paragraph Number 14. Biochemical Analysis. Enzyme immunoassays were used to determine concentrations of plasma acylated ghrelin (SPI BIO, Montigny le Bretonneux, France) and insulin (Mercodia, Uppsala, Sweden) with the aid of a plate reader (Expert Plus, ASYS Atlantis, Eugendorf, Austria). Plasma glucose and triacylglycerol concentrations were determined spectrophotometrically using a bench top analyzer (Pentra 400, HORIBA ABX Diagnostics, Montpellier, France). To eliminate inter-assay variation, samples from each participant were analyzed in the same run. The within batch coefficients of variation for the assays were as follows: acylated ghrelin $7.8 \%$, insulin $6.3 \%$, glucose $0.4 \%$ and triacylglycerol $2.7 \%$.

Paragraph Number 15. Statistical Analysis. Data was analyzed using the Statistical Package for the social Sciences (SPSS) software version 14.0 for Windows (SPSS Inc, Chicago, IL, U.S.). Area under the concentration verses time curve calculations were performed using the trapezoidal method. Student's $t$-tests for correlated data were used to assess differences between fasting and area under the curve values for acylated ghrelin, glucose, insulin, 
triacylglycerol, temperature, humidity and appetite between the control and brisk walking trials. Repeated measures, two-factor ANOVA was used to examine differences between the walking and control trials over time for body mass, appetite, energy and macronutrient intake, acylated ghrelin, glucose, insulin and triacylglycerol. The Pearson product moment correlation coefficient was used to examine relationships between variables. Correction of values for changes in plasma volume did not alter the statistical significance of findings therefore for simplicity the unadjusted values are presented. Statistical significance was accepted at the $5 \%$ level. Results are presented as mean \pm SEM.

\section{Results}

Paragraph Number 16. Brisk walking responses. Participants completed the 60 minute brisk walk at $7.0 \pm 0.1 \mathrm{~km} \cdot \mathrm{h}^{-1}$. This elicited a mean oxygen consumption equivalent to $45.2 \pm 2 \%$ of $\mathrm{VO}_{2}$ max (range: 33.8 to $55.5 \%$ ) and generated an average heart rate and net (exercise minus resting) energy expenditure of $137 \pm 6$ beats. $\min ^{-1}$ and $2008 \pm 134 \mathrm{~kJ}$, respectively. A mean non-protein respiratory quotient of $0.89 \pm 0.01$ reflected the proportional contributions of carbohydrate and fat $(61 \pm 3 \%$ and $39 \pm 3 \%)$ to energy provision. A median RPE value of 11 indicated that the intensity of the walk was perceived as 'fairly light' (range 10-12).

Paragraph Number 17. Baseline Parameters. No between trial differences existed at baseline in the plasma concentrations of acylated ghrelin, glucose, insulin, or triacylglycerol. Appetite perceptions were also no different at baseline (Table 2).

Insert Table 2 here 
Paragraph Number 18. Appetite and Energy Intake. Two-factor ANOVA revealed a main effect of time $(P<0.001)$ but no trial or interaction (trial $\mathrm{x}$ time) main effects for all appetite perceptions assessed (hunger, satisfaction, fullness and PFC), indicating that these appetite perceptions changed significantly over the course of trials but were not influenced by brisk walking (Figure 2). Two-factor ANOVA showed no trial or interaction (trial $\mathrm{x}$ meal) main effects for energy intake $(P>0.05)$. Thus, energy intake was not significantly different between the control and brisk walking trials. Moreover, energy intake was also no different between the morning meal and the afternoon meal during the control and brisk walking trials (Table 3). Examination of the relative energy intake (energy intake - (walking energy expenditure - resting energy expenditure)) showed that energy consumption was significantly reduced in the brisk walking trial compared to the control trial $(P<0.001)$. After adjusting for the energy expenditure of walking there was an energy deficit of $1836 \pm 130 \mathrm{~kJ}(439 \pm 31$ kcal) in the brisk walking trial compared with the control trial.

\section{Insert Figure 2 \& Table 3 here}

Paragraph Number 19. Macronutrient Intake. Table 4 shows the energy derived from the macronutrients in the control and brisk walking trials. There was no significant difference between trials in the quantity of energy derived from fat $(P=0.396)$. Fat intake tended to be higher in the afternoon meal than the morning meal $(P=0.053)$ however this tendency was no different between trials $(P=0.495)$. Likewise, carbohydrate intake was no different between trials $(P=0.969)$. Neither was carbohydrate intake significantly different between the morning and afternoon meals $(P=0.628)$ in either the control or brisk walking trials $(P=$ 0.862). Consumption of protein was no different between trials $(P=0.358)$. Protein intake 
did not differ significantly between the morning and afternoon meals $(P=0.461)$ in either the control or brisk walking trials (trial x meal interaction, $P=0.290$ ).

\section{Insert Table 4 here}

Paragraph Number 20. Plasma Metabolites. Plasma acylated ghrelin concentration changed significantly over time (two-factor ANOVA, $P=0.003)$. No trial $(P=0.922)$ or interaction (trial $\mathrm{x}$ time, $P=0.803$ ) main effects were found. The plasma concentration of acylated ghrelin was suppressed after consumption of the morning meal $(1.5-2 \mathrm{~h})$ and then rose prior to the afternoon meal $(5-5.5 \mathrm{~h})$ although the concentration did not reach fasting values. The afternoon meal also induced a suppression of plasma acylated ghrelin concentrations (Figure 3). Two-factor ANOVA revealed a main effect of time (all $P<0.001$ ) but no trial or interaction (trial x time) main effects for plasma glucose, insulin and triacylglycerol (Figure $4)$.

\section{Insert Figures 3 \& 4 here}

Paragraph Number 21. Correlations between acylated ghrelin and other variables. Fasting plasma acylated ghrelin concentration was not significantly correlated with body mass, BMI, waist circumference, body fat $\%$, maximum oxygen uptake, fasting insulin, fasting glucose or fasting triacylglycerol concentration. In the brisk walking trial acylated ghrelin and prospective food consumption area under the curve (AUC) were positively correlated during the intermeal interval $(1.5-5 \mathrm{~h})(\mathrm{r}=0.723, P=0.028)$. In the brisk walking trial acylated ghrelin and plasma triacylglycerol AUC were negatively correlated during the intermeal interval $(1.5-5 \mathrm{~h})(\mathrm{r}=-0.827, P=0.006)$ and across the total trial $(0-8 \mathrm{~h})(\mathrm{r}=-0.694, P=$ 
0.038). Acylated ghrelin and insulin AUC values tended to be negatively correlated across the total trial $(0-8 \mathrm{~h})(\mathrm{r}=-0.660, P=0.053)$.

Paragraph Number 22. When examining correlations at individual time points many significant relationships emerged. At 1 and $2 \mathrm{~h}$ during the control trial acylated ghrelin was positively correlated with hunger and prospective food consumption. Correlation coefficients ranged from 0.672 to 0.809 . During the control trial acylated ghrelin was negatively correlated with fullness at 1 and $2 \mathrm{~h}$, and with satisfaction at 1,2 and $5.5 \mathrm{~h}$. Correlation coefficients ranged from -0.716 to -0.898 . Inverse relationships were observed between acylated ghrelin and plasma triacylglycerol at $2.5 \mathrm{~h}$ in the brisk walking trial $(\mathrm{r}=-0.714, P=$ $0.031)$ and with plasma insulin at $5 \mathrm{~h}$ in the brisk walking trial $(\mathrm{r}=-0.744, P=0.022)$.

\section{Discussion}

Paragraph Number 23. The purpose of this investigation was to examine the appetite, energy intake and plasma acylated ghrelin response during and for several hours following a 60 minute bout of brisk walking. The main finding arising from this study is that despite inducing a moderate energy deficit an acute bout of brisk walking did not modify appetite, energy intake or the appetite stimulating hormone - acylated ghrelin. These findings lend support for a role of brisk walking in weight control.

Paragraph Number 24. The finding of no difference in appetite (hunger, satiety, fullness, PFC) between the control and brisk walking trials is consistent with previous work which has failed to observe an immediate difference in appetite following an acute bout of exercise (2). The relatively moderate intensity of exertion and subsequent energy expenditure elicited through walking may explain this finding. Previous work has consistently observed a 
suppression of appetite during and briefly following intense bouts of activity (> 60\% of $\mathrm{VO}_{2}$ max) (2). This response may therefore have been unanticipated in the present study as brisk walking provided a lesser physiological challenge to the relatively fit sample of participants examined.

Paragraph Number 25. Consistent with no change in appetite, brisk walking also failed to influence energy intake as in both the morning and afternoon meals energy intake was highly congruent between trials. This observation confirms previous findings which have typically shown no difference in energy intake in the short term $(1-2$ days $)$ following an acute exercise bout (2). Participants therefore failed to compensate for the exercise-induced energy expenditure. King and co-workers (22) have suggested that the relative post-exercise energy intake response (absolute energy intake adjusted for the net exercise induced energy expenditure) is of greater importance than the absolute amount of energy consumed. Using this formulae, in the present study brisk walking induced a relative deficit in energy in comparison with control $(1836 \mathrm{~kJ}, 439 \mathrm{kcal})$. This finding suggests that brisk walking does not elicit an automatic compensation in energy intake in the immediate hours following exercise. Although a more delayed response remains a possibility, this initial finding lends support for the utility of brisk walking in successful body weight control.

Paragraph Number 26. No change in macronutrient preference was detected between the control and brisk walking trials as in both the morning and afternoon meals the distribution of energy was typical of a Western diet. This observation confirms results from the majority of previous laboratory interventions which have failed to show any consistent effect of exercise on food preferences (14). In this investigation no change in macronutrient selection contributed to the lack of difference in energy intake observed between trials. Previous work 
has shown that switching from low-fat to high-fat food options completely reverses the energy deficit induced by prior exercise $(21,24)$. It is therefore appealing that brisk walking did not stimulate an appetite for foods with a higher content of fat and therefore energy.

Paragraph Number 27. To the authors' knowledge this study is the first to examine the acylated ghrelin response to brisk walking. Therefore, a novel finding is that plasma acylated ghrelin concentration is not affected during or for several hours after an acute bout of brisk walking. This finding is consistent with the lack of difference in appetite and energy intake observed between trials. Previously, a concomitant suppression of plasma acylated ghrelin and hunger has been observed during and briefly following an intense bout of treadmill running $(4,5)$. Brisk walking did not affect hunger in the present study, therefore, given the role of ghrelin in appetite regulation, no change in acylated ghrelin is a logical outcome. The reduced physiological challenge imposed by walking compared with running may account for the difference in findings between studies. In particular, an attenuated gut disturbance and/or redistribution of splanchnic blood volume during walking may be implicative. This finding indicates that acylated ghrelin is not sensitive to moderate deficits in energy induced via low intensity bouts of physical activity and holds positive implications for brisk walking in healthy body weight control.

Paragraph Number 28. In each trial acylated ghrelin was suppressed after the consumption of the morning meal, rose during the intermeal interval and declined again after the afternoon meal. This observation confirms previous findings regarding the temporal response of ghrelin to feeding $(9,10)$. The postprandial acylated ghrelin response may be related to an increase in plasma insulin concentration (1). The inverse relationship observed between insulin and acylated ghrelin across the walking trial lends support to this hypothesis. Meals high in fat do 
not suppress acylated ghrelin as efficaciously as those high in protein and carbohydrate (37). The significant inverse associations found between acylated ghrelin and triacylglycerol were therefore an unexpected finding in the present investigation. Further work is needed to illuminate the relevance of this.

Paragraph Number 29. This study has two notable limitations. Firstly, the sample of participants was composed of a relatively homogenous population of young, healthy males therefore the findings may not generalize to clinical populations. The homogeneity of the sample may also have prevented the detection of significant relationships between important variables such as fasting acylated ghrelin and anthropometric parameters. Secondly, appetite, energy intake and acylated ghrelin responses were observed merely for several hours after walking. Assessment of these variables over a greater period of time may be necessary in order to detect any compensatory responses.

Paragraph Number 30. In conclusion, this study demonstrates that an acute bout of brisk walking does not increase appetite, energy intake or plasma acylated ghrelin concentrations, despite inducing a moderate deficit in energy. This finding lends support for a role of brisk walking in successful weight management. Further work is now required to examine responses over a greater period of time and in other important populations including the elderly and the obese. Such findings will contribute to a greater understanding of the influence of walking on energy homeostasis.

\section{Acknowledgements}

We would like to thank the Ramblers Association for funding this investigation. We also wish to thank Mr. David Finney and Miss Louise Watkins for their help with data collection 
and all of the volunteers for their participation in this study. JAK recruited the participants, supervised the data collection, assisted with all aspects of the biochemistry and performed the data analysis. DRB and LKW assisted with data collection and provided assistance with the biochemical analysis. DJS obtained the funding and performed the venous cannulations. DJS and JAK conceived the study and wrote the manuscript.

None of the authors had any conflict of interest regarding any aspect of this study.

\section{References}

1. Awar R, Obeid O, Hwalla N, Azar S. Postprandial acylated ghrelin status following fat and protein manipulation of meals in healthy young women. Clin Sci. 2005; 109(4): 405-411.

2. Blundell JE, King NA. Exercise, appetite control, and energy balance. Nutrition. 2000; 16(7-8): 519-522.

3. Borg GA. Perceived exertion: a note on "history" and methods. Med Sci Sports. 1973; 5(2): $90-93$.

4. Broom DR, Batterham RL, King JA, Stensel DJ. Influence of resistance and aerobic exercise on hunger, circulating levels of acylated ghrelin, and peptide YY in healthy males. Am J Physiol Integr Comp Physio. 2009; 296(1): 29-35.

5. Broom DR, Stensel DJ, Bishop NC, Burns SF, Miyashita M. Exercise-induced suppression of acylated ghrelin in humans. J Appl Physiol. 2007; 102(6): 2165-2171.

6. Burns SF, Broom DR, Miyashita M, Mundy C, Stensel DJ. A single session of treadmill running has no effect on plasma total ghrelin concentrations. J Sports Sci. 2007; 25(6): 635642.

7. Caspersen CJ, Fulton JE. Epidemiology of walking and type 2 diabetes. Med Sci Sports Exerc. 2008; 40(7 suppl): S519-528.

8. Christ ER, Zehnder M, Boesch C, Trepp R, Mullis PE, Diem P, Décombaz J. The effect of increased lipid intake on hormonal responses during aerobic exercise in endurance-trained men. Eur J Endocrinol. 2006; 154(3): 397-403. 
9. Cummings DE, Frayo RS, Marmonier C, Aubert R, Chapelot D. Plasma ghrelin levels and hunger scores in humans initiating meals voluntarily without time- and food-related cues. Am J Physiol Endocrinol Metab. 2004; 287(2): E297-304.

10. Cummings, DE, Purnell JQ, Frayo RS, Schmidova K, Wisse BE, Weigle DS. A preprandial rise in ghrelin suggests a role in meal initiation in humans. Diabetes. 2001; 50(8): 1714-1719.

11. Dill DB, Costill DL. Calculation of percentage changes in volumes of blood, plasma, and red cells in dehydration. J Appl Physiol. 1974; 37(2): 247-248.

12. Donnelly JE, Blair SN, Jakicic JM, Manore MM, Rankin JW, Smith BK. American College of Sports Medicine Position Stand - Appropriate physical activity intervention strategies for weight loss and prevention of weight regain for adults. Med Sci Sports Exerc. 2009; 41(2): 459-471.

13. Durnin JVGA, Wormersley J. Body fat assessment from total body density and its estimation from skinfold thickness: measurements on 481 men and women aged from 16 to 72 years. Br J Nutr. 1974; 32: 77-97.

14. Elder SJ, Roberts SB. The effects of exercise on food intake and body fatness: A summary of published studies. Nutr Rev. 2007: 65(1): 1-19.

15. Erdmann J, Tahbaz R, Lippl F, Wagenpfeil S, Schusdziarra V. Plasma ghrelin levels during exercise - effects of intensity and duration. Regul Pept. 2007; 143(1-3): 127-135.

16. Flint A, Raben A, Blundell JE, Astrup A. Reproducibility, power and validity of visual analogue scales in assessment of appetite sensations in single test meal studies. Int J Obes. 2000; 24(1): 38-48.

17. Frayn KN. Calculation of substrate oxidation rates in vivo from gaseous exchange. $J$ Appl Physiol. 1983; 55(2): 628-634.

18. George VA, Morganstein A. Effect of moderate intensity exercise on acute energy intake in normal and overweight females. Appetite. 2003; 41(1): 43-46.

19. Imbeault P, Saint-Pierre S, Alméras N, Tremblay A. Acute effects of exercise on energy intake and feeding behaviour. Br J Nutr. 1997; 77(4): 511-521.

20. Kelly T, Yang W, Chen C, Reynolds K, He. Global burden of obesity in 2005 and projections to 2030. Int J Obes (Lond). 2008; 32(9): 1431-1437.

21. King NA, Blundell JE. High fat foods overcome the energy expenditure induced by high intensity cycling or running. Eur J Clin Nutr. 1995; 49(2): 114-123.

22. King NA, Burley VJ, Blundell JE. Exercise-induced suppression of appetite: effects on food intake and implications for energy balance. Eur J Clin Nutr. 1994; 48(10): 715-724. 
23. King NA, Caudwell P, Hopkins M, Byrne NM, Colley R, Hills AP, Stubbs JR, Blundell JE. Metabolic and behavioural compensatory responses to exercise interventions: barriers to weight loss. Obesity (Silver Spring). 2007; 15(6): 1373-1383.

24. King NA, Snell L, Smith RD, Blundell JE. Effects of short-term exercise on appetite responses in unrestrained females. Eur J Clin Nutr. 1996; 50(10); 663-667.

25. Kojima M, Hosoda H, Date Y, Nakazato M, Matsuo H, Kangawa K. Ghrelin is a growthhormone- releasing acylated peptide from stomach. Nature. 1999; 402(9): 656-660.

26. Kraemer RR, Castracane, VD. Exercise and humoral mediators of peripheral energy balance: ghrelin and adiponectin. Exp Biol Med (Maywood). 2007; 232(2): 184-194.

27. Kraemer RR, Durand RJ, Acevedo EO, Johnson LG, Kraemer GR, Herbert EP, Castracane VD. Rigorous running increases growth hormone and insulin-like growth factor without altering ghrelin. Exp Biol Med (Maywood). 2004; 229(3): 240-246.

28. Lee IM, Buchner DM. The importance of walking to public health. Med Sci Sports Exerc. 2008; 40(7 suppl): S512-S518.

29. Martins C, Morgan L, Truby H. A review of the effects of exercise on appetite regulation: an obesity perspective. Int J Obes (Lond). 2008; 32(9): 1337-1347.

30. Marzullo P, Salvadori A. Brunani A, Verti B, Walker GE. Fanari P, Tovaglieri I, De Medici C, Savia G, Liuzzi A. Acylated ghrelin decreases during acute exercise in the lean and obese state. Clin Endocrinol (Oxf). 2008; 69(6): 970-971.

31. Morris JN, Hardman AE. Walking to health. Sports Med.1997; 23(5): 306-332.

32. Murphy KG, Bloom SR. Gut hormones in the control of appetite. Exp Physiol. 2006; 89(5): 507-516.

33. Pomerleau M, Imbeault P, Parker T, Doucet E. Effect of exercise intensity on food intake and appetite in women. Am J Clin Nutr. 2004; 80(5): 1230-1236.

34. Sartorio A, Morurgo P, Cappiello V, Agosti F, Marazzi N, Gordani C, Rigamonti AE, Muller EE, Spada A. Exercise-induced effects on growth hormone levels are associated with ghrelin changes only in presence of prolonged exercise bouts in male athletes. J Sports Med Phys Fitness. 2008; 48(1): 97-101.

35. Siri WE. The gross composition of the body. Adv Biol Med Phys. 1956; 4: 239-280.

36. Taylor HL, Buskirk E, Henschel A. Maximum oxygen intake as an objective measure of cardio-respiratory performance. J Appl Physiol. 1955; 8: 73-80.

37. Tentolouris N, Kokkinos A, Tsigos C, Kyriaki D, Doupis J, Raptis SA, Katsilambros N. Differential effects of high-fat and high-carbohydrate content isoenergetic meals on plasma active ghrelin concentrations in lean and obese women. Horm Metab Res. 2004; 36(8): 559563. 
38. Toshinai K, Kawagoe T, Shimbara T, Tobina T, Nishida Y, Mondal MS, Yamaguchi H, Date Y, Tanaka H, Nakazato M. Acute incremental exercise decreases plasma ghrelin level in healthy men. Horm Metab Res. 2007; 39(11): 849-851.

39. Tsofliou F, Pitsiladis YP, Malkova D, Wallace AM, Lean ME. Moderate physical activity permits acute coupling between serum leptin and appetite-satiety measures in obese women. Int J Obes Relat Metab Disord. 2003; 27(11): 1332-1339.

40. Vestergaard ET, Dall R, Lange KH, Kjaer M, Christiansen JS, Jorgensen JO. The ghrelin response to exercise before and after growth hormone administration. J Clin Endocrinol Metab. 2007; 92(1): 297-303. 


\section{Figure Captions}

Figure 1. Schematic representation of the study protocol. Plasma glucose and triacylglycerol were determined from additional samples at 16 time points during each trial and insulin at 13 time points (not shown).

Figure 2. Perceptions of hunger (a), satisfaction (b), fullness (c) and prospective food consumption $(\mathrm{d})$ in the control $(\bullet)$ and brisk walking $(\circ)$ trials. Values are mean \pm SEM $(n=$ 14). Black rectangle indicates brisk walking - diagonally shaded rectangles indicate ad libitum meals.

Figure 3. Plasma acylated ghrelin concentrations in the control (•) and brisk walking (०) trials. Values are mean \pm SEM $(n=14)$. Black rectangle indicates brisk walking - diagonally shaded rectangles indicate ad libitum meals.

Figure 4. Plasma concentrations of triacylglycerol (a), insulin (b) and glucose (c) in the control $(\bullet)$ and brisk walking $(\circ)$ trials. Values are mean \pm SEM $(n=14)$. Black rectangle indicates brisk walking - diagonally shaded rectangles indicate ad libitum meals. 


\section{Appendices}

Appendix A: Items presented at buffet meals

\begin{tabular}{c}
\hline Coco-pops ${ }^{\circledR}$ - Cereal \\
Cornflakes ${ }^{\circledR}$ - Cereal \\
Rice Krispies - Cereal \\
Frosties ${ }^{\circledR}$ - Cereal \\
Milk \\
Cereal Bar \\
White Bread \\
Brown Bread \\
Tuna \\
Cheese \\
Ham \\
Butter \\
Mayonnaise \\
Salted Crisps \\
Apple \\
Orange \\
Banana \\
Chocolate rolls \\
Chocolate muffins \\
Plain muffins \\
Cookies \\
Chocolate bar (Mars fun size $\circledR)$ \\
\hline
\end{tabular}


Table 1: Participant characteristics. Values are mean $\pm \operatorname{SEM}(n=14)$.

Characteristic

\begin{tabular}{cc}
\hline Age $(\mathrm{yrs})$ & $21.9 \pm 0.5$ \\
BMI $\left(\mathrm{kg} \cdot \mathrm{m}^{-2}\right)$ & $23.4 \pm 0.6$ \\
Body Fat $(\%)$ & $19.2 \pm 1.2$ \\
Waist Circumference $(\mathrm{cm})$ & $81.0 \pm 1.5$ \\
$\mathrm{VO}_{2} \max \left(\mathrm{mL} \cdot \mathrm{kg}^{-1} \cdot \mathrm{min}^{-1}\right)$ & $55.9 \pm 1.8$ \\
\hline
\end{tabular}


Table 2: Baseline metabolite and appetite values in the control and brisk walking trials. Values are mean $\pm \operatorname{SEM}(n=14)$. PFC $=$ Prospective food consumption.

\begin{tabular}{cccc}
\hline & Control & Brisk Walking & $P$ \\
\hline Acylated ghrelin (pg.mL & & \\
Glucose (mmol.L $\left.\mathrm{L}^{-1}\right)$ & $81.4 \pm 9.1$ & $93.2 \pm 22.3$ & 0.507 \\
Insulin (pmol.L $\left.\mathrm{L}^{-1}\right)$ & $4.49 \pm 0.2$ & $4.41 \pm 0.2$ & 0.520 \\
Triacylglycerol (mmol.L-1) & $27.5 \pm 5.2$ & $30.1 \pm 5.0$ & 0.671 \\
Hunger (0-100) & $0.82 \pm 0.1$ & $0.78 \pm 0.1$ & 0.462 \\
Satisfaction (0-100) & $55 \pm 7$ & $58 \pm 6$ & 0.718 \\
Fullness (0-100) & $29 \pm 7$ & $29 \pm 6$ & 0.972 \\
PFC (0-100) & $29 \pm 7$ & $27 \pm 6$ & 0.647 \\
\hline
\end{tabular}


Table 3: Energy intake during the control and brisk walking trials. Values are mean $\pm \operatorname{SEM}(n=14)$. Values presented are $\mathrm{kJ}$ and (kcal).

\begin{tabular}{ccc}
\hline & Control & Brisk Walking \\
\hline Morning meal (1.5-2 hours) & $4483 \pm 378$ & $4520 \pm 436$ \\
& $(1072 \pm 90)$ & $(1080 \pm 104)$ \\
Afternoon Meal (5-5.5 hours) & $4729 \pm 348$ & $4864 \pm 490$ \\
& $(1130 \pm 83)$ & $(1163 \pm 117)$ \\
Total Trial & $9212 \pm 588$ & $9384 \pm 659$ \\
& $(2202 \pm 141)$ & $(2243 \pm 157)$ \\
\hline
\end{tabular}


Table 4: Energy derived from the macronutrients during the ad libitum buffet meals in the control (upper panel) and brisk walking (lower panel) trials. Values are mean $\pm \operatorname{SEM}(n=14)$. Values presented are grams and $(\%)$.

\begin{tabular}{cccc}
\hline Control & Fat & Carbohydrate & Protein \\
\hline Morning Meal (1.5-2 hrs) & $37.7 \pm 4.9$ & $143.5 \pm 8.3$ & $39.5 \pm 8.8$ \\
& $(31.7)$ & $(53.6)$ & $(14.7)$ \\
Afternoon Meal (5-5.5 hrs) & $45.5 \pm 4.5$ & $137.2 \pm 16.2$ & $43.1 \pm 7.4$ \\
& $(36.2)$ & $(48.5)$ & $(15.3)$ \\
Total Trial & $83.2 \pm 7.9$ & $280.7 \pm 20.4$ & $82.6 \pm 14.8$ \\
& $(34.0)$ & $(51.0)$ & $(15.0)$ \\
& & & \\
\hline Brisk Walking & Fat & Carbohydrate & Protein \\
\hline Morning Meal (1.5-2 hrs) & $35.3 \pm 4.4$ & $149.0 \pm 13.5$ & $41.7 \pm 8.8$ \\
& $(29.4)$ & $(55.2)$ & $(15.4)$ \\
Afternoon Meal (5-5.5 hrs) & $44.2 \pm 5.6$ & $141.2 \pm 13.9$ & $50.1 \pm 10.2$ \\
& $(34.2)$ & $(48.6)$ & $(17.2)$ \\
Total Trial & $79.5 \pm 8.1$ & $290.2 \pm 19.4$ & $91.8 \pm 15.5$ \\
& $(31.9)$ & $(51.7)$ & $(16.4)$ \\
\hline
\end{tabular}




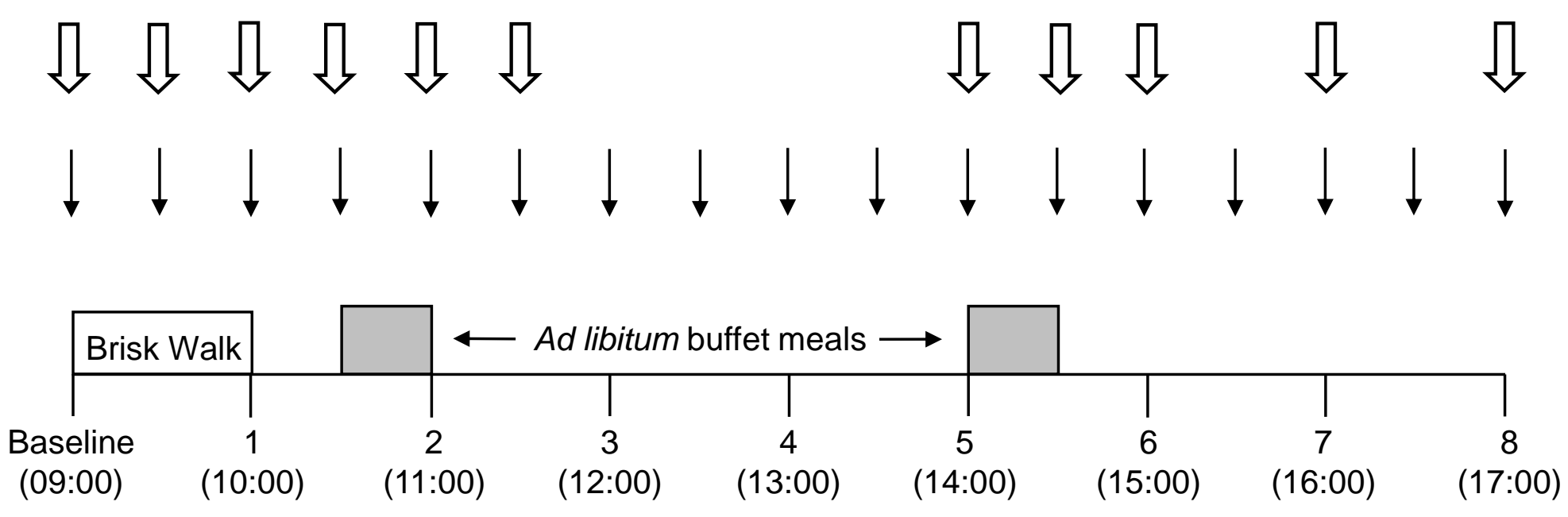

Time in hours (approximate time of day)

\footnotetext{
$\sqrt{ }$ Plasma acylated ghrelin sample

$\downarrow$ Appetite measurement
} 

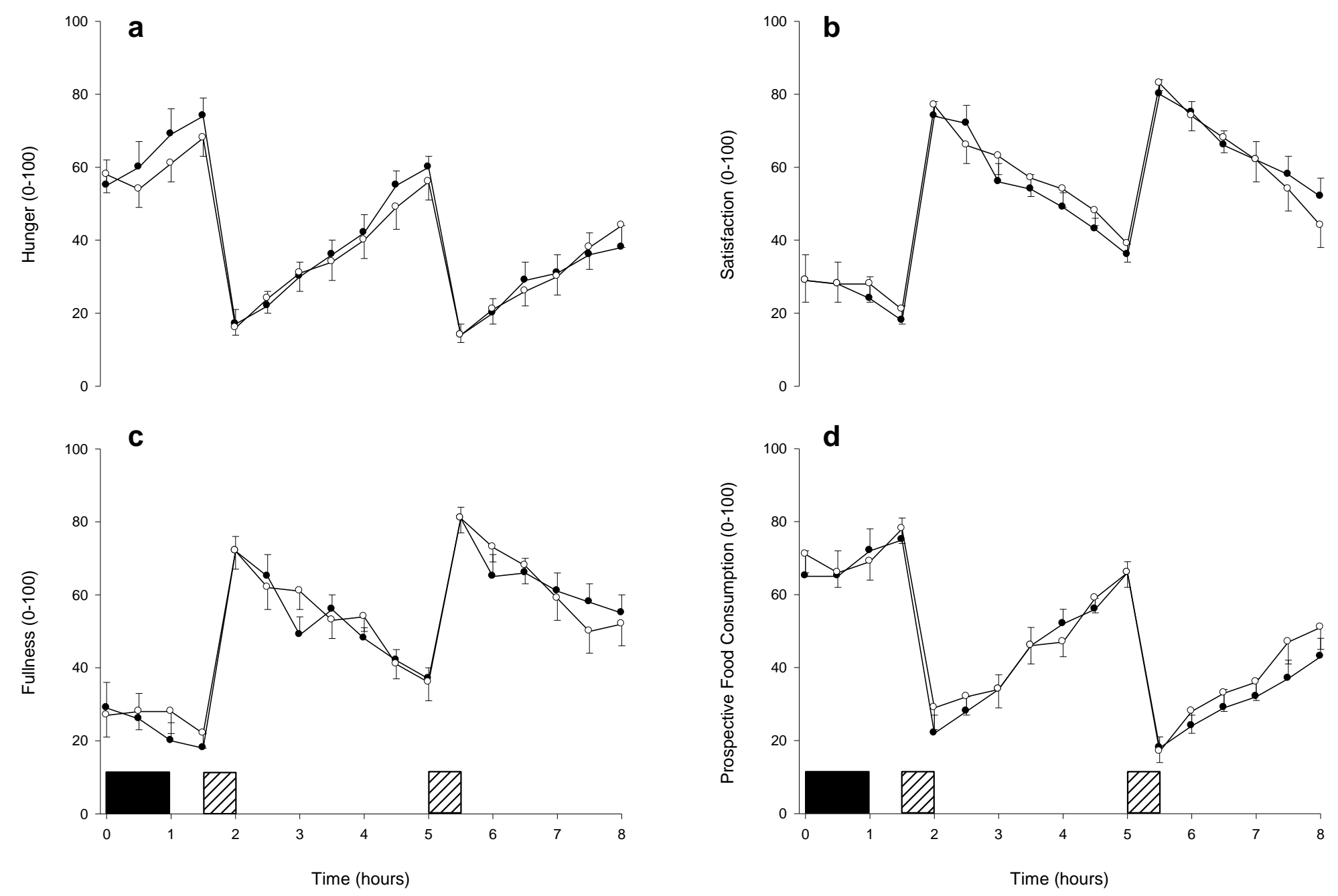


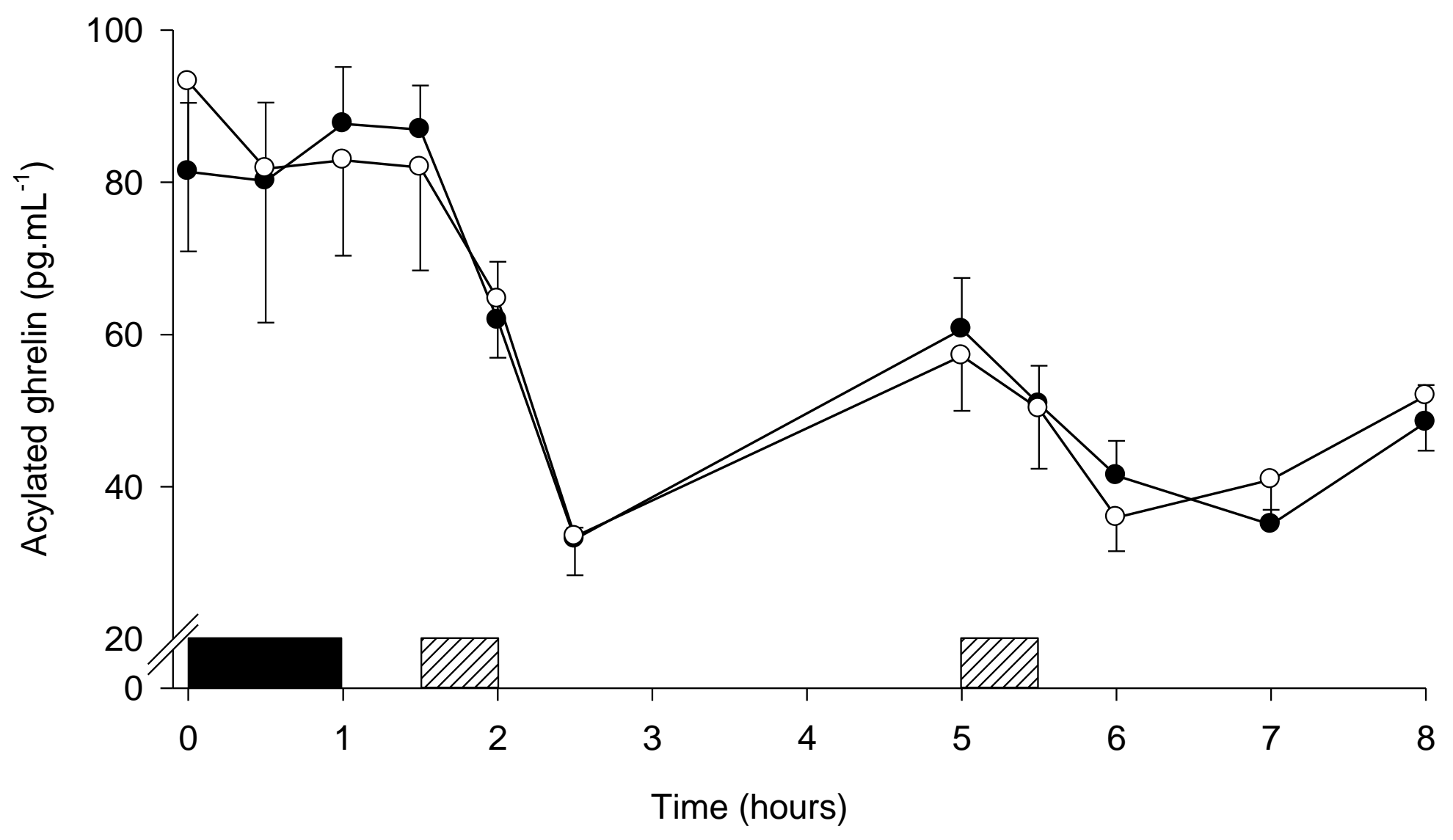



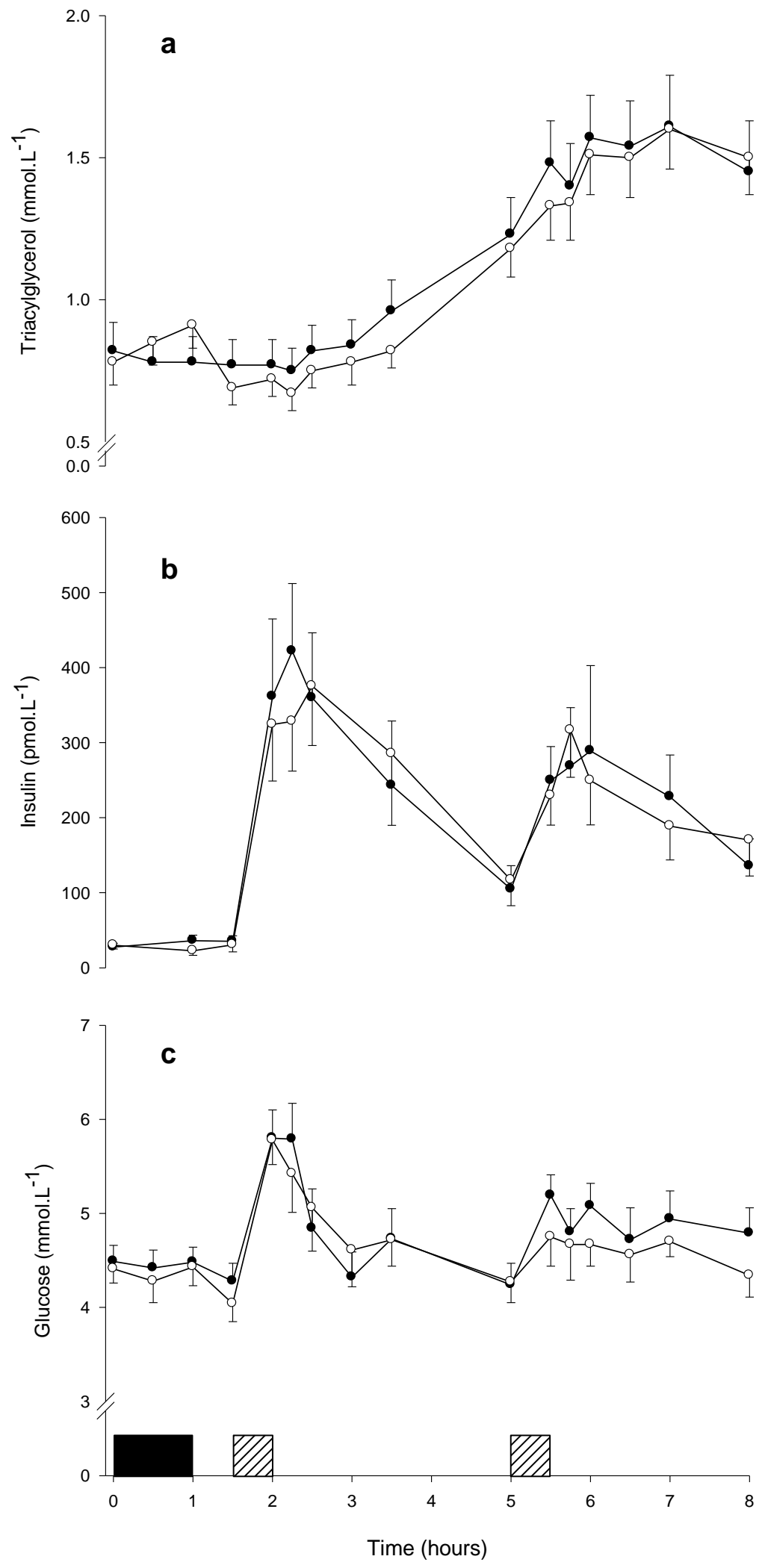